\title{
Enhancing the Culture of Quality Assurance in Higher Education: Perspectives of Managing Institutional Accountability
}

\author{
Jacob M Selesho \\ Faculty of Management Sciences, Vaal University Technology, \\ Vanderbijpark, South Africa \\ jmselesho@gmail.com
}

\section{Doi:10.5901/mjss.2014.v5n1p405}

\section{Abstract}

Accountability and quality enhancement are related but not the same thing. Accountability is the context where universities account to the public with regard to public funding pertaining academic offerings, while quality enhancement is the role of the university in ensuring that it deliver academic programme at the highest standards. Thus, this paper sought to understand the role of academic leadership in the management of quality enhancement, stakeholder engagement and entrepreneurialism. The researcher made use of the descriptive survey as it fits perfectly in this kind of study. Questionnaires and structured interviews were utilised. The purpose of using the qualitative research method is to describe role of accountability process, however the researcher have decided to use idiographic strategy, in which a single case and its structural coherence with a larger context are examined. The population of this study consists of all six Universities of Technology. From all deans, heads of department and programme coordinators the researcher selected only 135 from UoT's, as they were able to participate in the study. For the purpose of this study, questionnaire was developed to measure various aspects of QA mechanisms, processes and procedures. To defend the study of quality enhancement structures, the researcher refutes the idea of a quality model as only one way of solving the problem scientifically. Therefore, suggesting various elements that can be put together will assist UoTs in their quest for QA. To prepare to refute the claim, the research embraces the issue of academic leadership role in quality assurance, stakeholder engagement as part of the accountability part and finally business model affordability. The object of scientific enquiry exists and acts independently according to the requirement as set out by the HEQC and this analysis inform realities of the HE landscape and who quality should be guided within the institution. New academics are confused by finding themselves that QA in HE is not what they thought to be.

Keywords: Enhancement, Quality, Engagement, Stakeholder, Entrepreneurialism

\section{Introduction}

For many years quality assurance of teaching and learning has been on the university agenda for quite some times. However, universities have not done much to improve or reshape these important pillars of the university operations (Bitzer, 2010). The universities have not yet developed a well-functioning quality management model that would guide and assist the academic enterprise to grow. While Bitzer (2010), argue that in most cases external people will critique university on the basis of its academic offerings, these people will cooupy the role of being labelled as external stakeholders. Although, many authors (Harvey 2004; Stensaker 2007; Newton 2007; argues that the concept of quality is not new; it has always been part of the academic tradition.

It is the outside world that now emphasises the need for attention to quality assurance (QA), with the relationship between higher education institutions (HEIs) and society having changed. This encapsulates the profound changes in the context of higher education (HE); including growth, diversity, changes in size and in the nature of HE. This has been accompanied by a growing state interest in quality, demands for accountability and the establishment of national quality agencies (Newton, 2007:14). The notion of quality covers those elements of an HEI culture that have the strongest impact on quality teaching.

It must be emphasised that in studies of quality culture, with respect to HEls, this concepts is perceived mainly in terms of the total quality management (TQM) philosophy, which reveals the role of leadership in creating a culture based on the constant need for improvement, team work and the participation of all in the process making (Kowalkiewicz, 2007:63). According to Kowalkiewicz (2007:63), the majority of HEls have focused on working out the procedures of quality evaluation and assurance, which may appear insufficient if not accompanied by the evolution of the university organisational culture towards a quality culture, since what is crucial for the success of any action aimed at quality 
enhancement, is a quality-orientated system of values. This visible determinant seems to be underestimated by universities in striving for high quality teaching (Okebukola, 2006:3-5). Academic quality results from the leadership that develops the best-in-class policy and strategy, customer and market focus and people management with the academic and efficient use of resources.

Given South Africa's history with its discrepancies between historically disadvantaged institutions and historically advantaged institutions, quality assurance as a phenomenon, will not be accepted by all in the HE community with equal eagerness. Universities of Technology (UoT's) and Historically Disadvantaged Institutions (HDI's), with a long history of being defendant of poor academic quality standards might well be offended.

Within the context of transformation in HE in South Africa, majority of UoT's and HDI's have been challenged in two important ways: the challenge of equity with regard to students admission as well as staffing and research output.

Quality in HE depends primarily on the commitment of the academic community to the maintenance and improvement of standards. In South Africa, the government has established the Council for HE as a major statutory body to provide independent strategic advice to the Minister of Education on matters relating to the transformation and development of HE in South Africa, and to manage QA and quality promotion in the HE sector (Du Pre, 2000:7). For HE institutions to attract new undergraduate students, they are increasingly being expected to satisfy the student's needs by offering creditable qualifications, in a form that meets or even exceeds customer expectations (Dill, 2003:11).

\section{Quality Mechanisms: Placing the Responsibility for QA on the Hei}

Though is it generally agreed that the primary responsibility for quality assurance and improvement rests with the individual HEls, the establishment of QA agencies in some African countries has been perceived as transferring the responsibility for QA to an external body.

\subsection{Management and Leadership during the quality process}

Integrated institution requires both leadership and management. While these should be distinguished, they should also be seen as complementary to ensure success. It is further emphasised by Szanto (2003:10) that the communication Flow and Decision-taking Network also notes that "while management is adequate for stable and known activities ('operations'), leadership is really needed for unstable and uncertain activities.

While the importance of the leadership cannot be minimised, this network also highlights the importance of the development of professional expertise in the administrative structures of these universities that have had a traditional collegial organisation. Paradoxically, when a university relies on academics to run the administrative service this can lead to over-bureaucratisation (Tempus, 2001).

Thus, "Quality culture aims at the creation of engagement and conviction with stakeholders to meet and improve leaning objectives" and to ensure a bottom-up approach to quality. By contrast, quality management is the technocratic side of quality culture and refers to "tools and mechanism to measure, evaluate, assure and enhance quality. In this sense quality management is closed to a top-down approach to quality culture". The report further points out that both elements are essential and must be mediated by effective communication and participation (Tempus, 2001). 
Diagram 1.1: The Planning Process

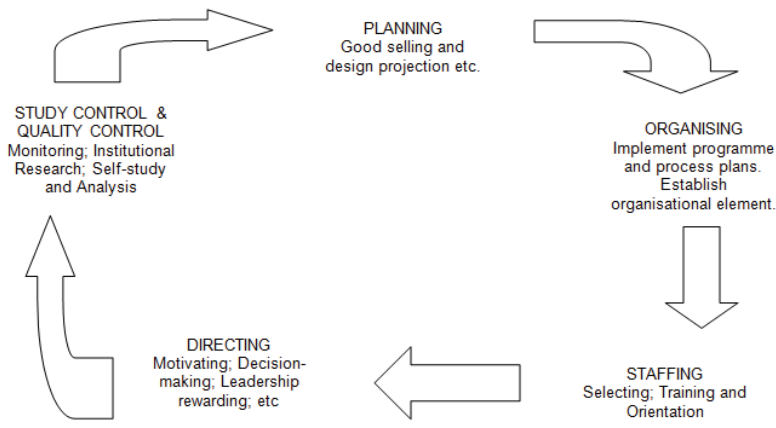

Source: Jacobs, 2000

In designing a management system which plans to include QA of the education provided, the University of La Verne in Southern California researched the prevailing systems operating in industry. Such systems have become the norm against which industry judges other systems of education (Jacobs, 2000:48). Each HEl's is, however, faced with the dilemma of addressing quality from three reference points: how quality is understood by the institution; how it is perceived more universally in HE as presented through the accreditation associations; and how it is perceived by the customers. Quality Agencies have produced generally acceptable norms of conduct usually expected of HEls. The values, mission and aims of the institution should first be identified and established before an academic quality model can be developed (Mapesela \& Hay, 2005).

\section{Planning QA Management: External QA (EQA) in Hei's QA Systems}

Social demand for HE has been on the increase over the past few decades. This has resulted in increased enrolments, although the financial capacity has often been inadequate. Given a frequently insufficient financial capacity to respond to the social demand for $\mathrm{HE}$, many countries worldwide that were formerly committed to exclusive public systems of education, have adopted legislation that allows for the development of a system of private HE (Luckett, \& Kotecha, 2005). This has led to a tremendous growth in $\mathrm{HE}$ institutions which have also undergone a major privatisation process through a growing reliance on cost-sharing arrangements and income-generation measures (Yorke \& Longden, 2004).

In many countries, governments have redefined their roles as public authorities under the 'new public management' concept, which suggests - as one of its pillar ideas - greater reliance on the deregulation and decentralisation of power from the government or its agencies to institutions (Luckett, \& Kotecha, 2005). In many countries, deregulation has become part of a broader reform of public organisations, where the decentralisation of decision-making incentives for units and individual staff, the negotiation of objectives and targets, as well as output control and a funding system based on output measures, are the predominant tools (Yorke \& Longden, 2004 Luckett, \& Kotecha, 2005;).

However, the demand for accountability and trust is also raised on political agendas, together with greater freedom for higher education institutions to take decisions at their own discretion (Fernandez, Fernandez \& Alvares, 2008). Governments expect institutions to be accountable to their students and the public as a whole for the quality of their services and the utilisation of resources. Consequently, institutions in many countries worldwide have been urged to provide information on their results, as well as on their expenditure (Jongbloed, 2007).

\section{Models of Responsiveness}

A rapid and profound change in the global economy and the phenomenon of globalisation have focused greater attention 
in recent times on the need for engagement between $\mathrm{HE}$ and business as the major producers of knowledge resources and knowledge workers. In response to these dynamics, government, business and HE institutions in South Africa are concerned about ensuring that they become more responsive to private and public partners, as well as being more globally competitive (Chetty, 2005:6).

In $\mathrm{HE}$ the shift towards a more responsive entrepreneurial, managerial and cost-conscious culture has had a major influence on recent developments in South Africa. Pressures from the external context, and the forces driving system level change, clearly point to the emergence of newer and more complex forms of engagement between the three sectors - engagement that deserves closer attention. HE institutions can ignore neither the challenge from other knowledge producers, employers and students, and other education providers, nor the challenge of new technologies (Chetty, 2005:6).

\subsection{Theorising the transition: Motivations}

Traditionally, the relationship between South African HE and business was based on the narrow interests of particular industries, concentrated in historically white institutions (predominantly in the form of universities), and centred on research funding, contracted research services, bursaries, scholarships and endowments. The state was the primary funder of $\mathrm{HE}$, and student fees, research income and other sources were either modest or negligible sources of income. This situation could be described as a more or less 'industrial mode' - before globalisation and the knowledge economy had taken hold.

Two factors have radically altered the dynamics between government and institutions: funding and policy. Firstly, in terms of funding, the reality of post-1994, is that the state can no longer afford to support HE institutions at the same levels as previously and all institutions are implicitly expected to develop and generate other sources of income. In terms of policy, the state is now the funder of 'last resort', as defined by the new funding policy (Department of Education, 2003). As a result, entrepreneurial initiatives are increasingly focused on maximising, in the short term, what has come to be known as ' 3 rd stream income'. Secondly, regulatory policy in the sector has redefined the mission of HE in ways that require a far more concerted engagement with business in the interest of promoting responsiveness, relevance, economic growth and high skills development objectives (DoE, 2006:11).

South Africa is often compared and contrasted with other countries and the global economy with arguments posited for focusing more on responsiveness from the HE sector. While this might seem a more manageable and useful goal than focusing on competitiveness, it nevertheless introduces the problem of how to deal with the reality of widely divergent notions of 'responsiveness' and 'relevance'. For example, Kruss explores the responsiveness of HE in the context of employment and employability. In its own assessment, the CHE worked on setting the 'ground rules' in place for a greater engagement with the private sector and to explore the modalities to ensure a sustainable, productive relationship. Others have argued a case for HE institutions to be more focused on 'broader national interests': poverty eradication, social renewal and the strengthening of the public sector (Chetty, 2005:6-9).

This suggests that the knowledge economy will provide for a considerably higher level of human development than the industrial economy, for the conversion of what we know as the 'labour force' into 'knowledge workers', and for a significant expansion in investment in education, training, research and development - the major formal knowledge generating activities. It also suggests a more widespread distribution of the wealth generated in the knowledge economy because the human resources attracting this increased investment are also workers and consumers (Kraak, 2002:15).

Increasingly large and complex institutions of higher learning demand the application of professional management techniques, strategic vision, and more proactive corporate management styles that address problems through innovation, and governance structures that facilitate institutional responsiveness to the wide range of university stakeholders. These shifts have been slow to materialise within Nigerian universities. The transition towards more flexible management and governance could be assisted by a national training capacity in university management, a budget allocation process that recognises institutional performance and financial management that empowers strategic planning and decentralised governance (Bashir, 2002:2-3).

At this point, the government's policy reform package has been adequately designed but possibly not well explained to HE stakeholders. University officers and governing councils have been largely passive observers of the announced reforms, instead of taking on the role of change agents. Vocal opposition has come from the Union of Universities and from students. Statements from these groups suggest that their resistance is based less on the substance of autonomy legislation, and more on fears of government's hidden agenda to commercialise and privatise HE. Three major models, which have been advocated by Chetty (2005) and Favish (2005), have influenced thinking 
about responsiveness of $\mathrm{HE}$, entrepreneurialism; stakeholder engagement and management.

\subsection{Entrepreneurial model}

The first model described here is that of the entrepreneurial university. According to Favish (2005:110) entrepreneurial institutions have positioned themselves to respond to the needs of business and industry as a way of generating additional sources of income for HE. The emergence of the entrepreneurial university has contributed to changes in the form, focus and dissemination of knowledge and management of HE as evidenced by the commodification of knowledge, the growth in funded research, the transfer of management practices from the private sector into public $\mathrm{HE}$, the focus on technology transfer and a fragmentation of teaching and research. Szanto, among others, has argued that these kinds of developments, while meeting particular needs of the institution and industry, could have the effect of undermining the role of HE in contributing to equity, community development and the public good (Favish, 2005:110).

\subsection{Community engagement model}

Significantly, academic arguments in support of local engagement have also been advanced. Such arguments reflect new ideas about the curriculum for $\mathrm{HE}$, which centre on a growing belief that the best universities will be those that adapt and creatively reconfigure knowledge to solve problems. This involves a shift from Mode 1 (basic) knowledge production to Mode 2 knowledge production (knowledge produced in the context of application) (Favish, 2005:110).

A model similar to that of the civic engagement one - similar in that a strong emphasis is placed on civic responsibilities - is the model of seeing universities as sites of democracy and civic responsibility or as sites of citizenship (Favish, 2005:110).

\section{Research Methodology}

In this section the methodology used in the study is highlighted and unpacked for the smooth organisation of the process. The researcher made use of the descriptive survey as it fits perfectly this kind of study. The purpose of using the qualitative research method is to describe role of accountability process. Qualitative data were gathered in as many ways as the researcher's creativity permitted (McMillan \& Schumacher, 2007). Although the most widely used sources were observation and interviewing, an analysis of records and documents is common, and it was also used.

The research strategy is idiographic, in which a single case and its structural coherence with a larger context are examined. Cohen, Manion and Morrison (2007:6-9) indicate, that should one favour the views on social reality that stress the importance of the subjective experience of individuals in the creation of the social world, the search for an understanding should focus on different issues and be approached in a totally different way.

\subsection{Population and sample}

The population of this study consists of all six Universities of Technology (UoTs), academic heads of department (HODs) and quality assurance managers (QAMs). From all deans, heads of department and programme coordinators the researcher selected only 135 from UoT, as they were able to participate in the study.

\subsection{Data collection and Instrumentation}

Interviews were conducted, supplementary to the administration of questionnaires. Permission for data collection was applied for and obtained from the institutional QA manager. A research instrument is a measuring device used to evaluate more precisely the behaviour being studied. The particular instrument used, depends on the nature of the investigation. Qualitative researchers may use different approaches in collecting data, such as the grounding theory practice, narratology, or storytelling, to mention but a few. The measuring instruments used in this study, were questionnaires and interview sessions.

\section{Results of the Study}

The QA system is intended to support the achievement of the purpose and goal of HE identified in White Paper 3 of 
1997. Quality is identified as one of the principles that should guide the transformation of HE, together with equity, effectiveness and efficiency. The White Paper 3 of 1997 identified funding, equity, enrolment planning and QA as key factors for steering the reconstruction and transformation of South African HE and the creation of a HE landscape that is progressively characterised by equitable, high quality and sustainable institutions that are well governed, managed and responsive to the needs of economic growth and social development, and to the consolidation of democracy.

Figure 1.1: Government Policy Development Model

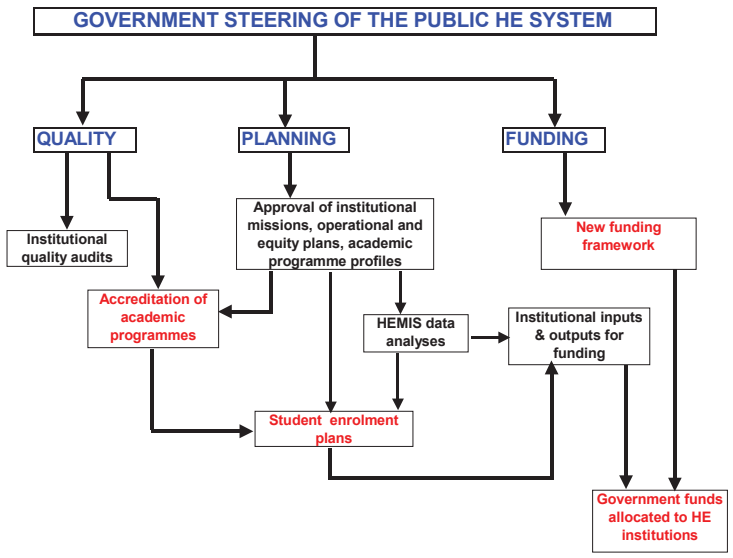

In my interview with one HE specialist, this is what he had to say: "If academic practitioners complain about the imposition of policy by the government then that is where they are missing the whole point. I will present a model to you as part of the government consultative forum with various stakeholders. Education Minister did set up a task team which, for that matter, was dominated by academics". The purpose of the task team was to consolidate issues and informing pave way for $H E$.

\section{Availability of a Quality System for Academic Programmes}

The empirical findings reveal that various institutions are doing much in trying to build internal quality systems. Institutions themselves provide training workshops, seminars and conferences to ensure that their internal structures are improved. These capacity building programmes are facilitated through the office of the QAM, or in some instances, request assistance from other institutions or from the capacity development section of the HEQC.

The qualitative analysis also measured the availability of the management of quality, stakeholder engagement and entrepreneurship their respective HEls, and aimed to establish if they were actually effective. This is how the HODs responded.

Figure 1: Institutional Profile

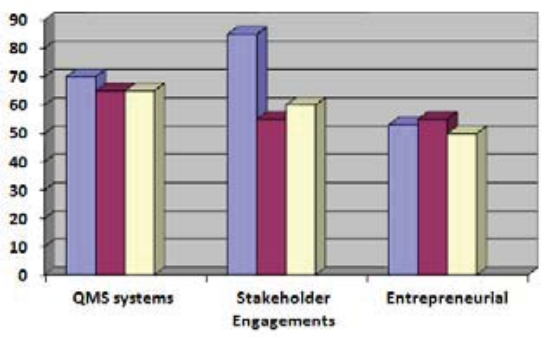

While the 135 respondents were surveyed on three factors that have an impact on the institutional role of both academic 
management, $70 \%$ senior academic managers, $85 \%$ of Heads of Department and $55 \%$ of programme coordinators were of the view that their respective institutions have one or another developed a system of managing quality of teaching and learning in the Faculties, department and academic programmes. Respondents did confirm that although they are trying to ensure that there are some sort of stakeholder engagement in their respective. The issue of stakeholders' engagement was extended to the role that advisory committee and other oversee committee play in the university quality of teaching and learning. The study examined the promotion of accountability in consideration with quality promotion as expected by the stakeholders. It was in this rapprochement that HODs felt their job profile has shifted to the direction of quality compliance, enhancement and fundraiser as compared to their administrative roles and responsibilities. Despite an element of openness when they had completed the questionnaires and through some discussions, the researcher could detect that some were guarded in their responses to certain questions. Interestingly, most of the HODs expressed their satisfaction with and acceptance of the expectation with regard to quality enhancement; according to one respondent, it was of a high standard as she said: "we have more processes and capable leadership that we can work from". Another said: "It is clear, easy to understand and to follow". Nevertheless, some respondents felt that there is no direction at all but did not rule out the possibility of getting assistance, as they struggled to work with what is available. Unfortunately, this does not necessarily suggest a particular problem regarding our approach, but presents a true picture of what the deep-rooted challenges are that face these institutions. Moreover, due consideration should be given to the new funding framework of 2006/7 to 2007/8, the main intention of which was to direct HEls towards the attainment of the National Plan of Higher Education, which in the case of this study, is QA but the focus was also on reposition HEls to reflect their entrepreneurial approach.

From figure 1, the analysis is as follows: $60 \%$; $58 \%$ and $50 \%$ of respondents replied that HEl's are not implementing any business model in terms of creating a third stream income. From HoD's (58\%) and programme coordinator (50\%), it became clear from their responses that raising the business profile of the academic qualifications as well as the quality assurance of the short learning programme is not their role. They obviously adopted an approach that the executive must take the lead in the business venture of the academic programme.

The analysis of the submissions indicates that $93 \%$ of the institutions had some sort of policy on QA. However, in most cases these policies have not yet been translated into plans and strategies. There was not much available documentation, such as manuals or regulations, reflecting QA arrangements. Irrespective of how policy-makers within the institution, as well as institutional leaders may decide to shift and place the focus on policy implementation and its discourse and practice; critical questions pertinent to the relevance and academic worth of the institution and its learning programme, will always engage quality scrutiny and enquiry into issues pertaining to the public good.

"In our institutions financial incentives, being in the form of grants or other special mechanisms, really assist us in creating support programmes for novice researchers. The university has a plough-back policy, by using the research earnings generated from Master's and Doctoral funding to improve the research capacity as these qualifications are considered as quality indicators."

\subsection{Quality Assurance and Quality Enhancement}

However, it is also possible to perceive of a positive symbiotic relationship between the two components; that they are in effect, interactive processes in the improvement of an institution's teaching and learning mission. Thus, for one QAM "the only purpose I can think of to QA is quality enhancement". Another QAM asserted: "that's where your QA procedures come in; they tell you if you are meeting certain standards and alert you to areas which you need to improve. The issue is whether a positive relationship will indeed evolve, or whether quality enhancement will become little more than a new model of quality assurance simply camouflaged by a different descriptive label? In other words, how is a concept that potentially offers a different interpretation of the quality agenda actually to be realised in practice?"

\subsection{Institutionalization of quality enhancement}

The most critical challenge to the idea of quality enhancement is posed by its institutionalization. Conventions for quality enhancement need to be defined and systematic structures constructed to develop its practices. Inevitably, the unfolding of its process forces a return to the question of who has the power to determine the meaning of the key concepts, how are they to be put into effect even in institutions that apparently endorse them and what should the policy outcomes be?

Regardless of what model should be constructed, the key area to explore is that of what is happening on the ground, i.e. in the universities; how the two bodies HEQC and QAM interact with each other and relate to the universities, 
and how the representative institutions will respond to the emerging outcomes.

However, there are those who remain sceptical. In the words of one senior quality officer: "Quality enhancement has become more talked about, more promoted and the HEQC audit methodology says that it encourages quality enhancement but I'm not convinced. I'll wait until we've gone through one; the rhetoric is there but I think they're going to come in and see what our procedures are like, as they have always done. There's no sign that they're going to focus on things that might encourage us to really take the enhancement side more seriously. The development of the quality agenda suggests that ideas and power struggles are intimately interrelated but their visibility varies as policy unfolds: ideas become more prominent as policy is formulated. Politics dominates the formal construction of policy (legislative process) while both politics and the ideological struggle interact at the implementation stage.'

\section{Admission to and Througput Rate from the Programme}

In yet another department, one HOD, where enrolment had moved approximately to double the initial enrolment, the staff complement had not seen any proportionate increase, with the result that many lecturers were faced with teaching very large classes. Thus, the quality of the educational offerings was undermined and posed the problems of limited creativity and flexibility in assessment approaches, which to a certain degree, impacted on the throughput rate as compared to enrolment planning. In order to ensure that quality assurance is applied effectively at the institutions of $\mathrm{HE}$, these institutions need to address their throughput rate. The institutions should consider the following questions regarding admission criteria.

(a) What admission and selection policies/criteria are in place?

(b) How is equity of opportunity for all applicants secured?

(c) How is part-time student recruitment managed?

It was necessary to include this type of question in the questionnaire to establish how an institution controls its quality regarding the admission of students. The respondents answered the question of admission criteria by looking at the practical implications and not at the policy procedure of the institution. Most respondents, namely $77 \%$, indicated that they agreed with the statement that the admission criteria applied in their programmes were appropriate; $23 \%$ of the respondents raised concerns that the admission criteria applied in their programmes were not appropriate.

\section{Conclusion}

It is hoped that this study has helped to provide relevant information that can be used to assist UoTs to support, change or build a QA model that would be of great value to the institution. In addition, the study attempted to address issues or elements that can build a strong quality culture model; for stakeholder engagements, quality enhancement entrepreneurial flair. Although we can agree with or contest the idea of political interference, it is important to realise that this presents a paradigm shift in the understanding of what quality actually means to us; that is, the culture of accountability and compliance with national imperatives. It is in this regard that the study outlined the national HE DoE structure in order to assist UoTs with compliance issues and to emphasise that strong institutional policies be built on, together with a monitoring process to ensure compliance. Institutional self-evaluation principles are in actual fact very simple, indicating that QA is evidenced-based and that logic is an active force in making it a success. It is recommended that clearly defined concepts linked together to form a coherent system should be employed to build a strong selfevaluation report. This system makes the results more valid as prior planning is undertaken accordingly.

It cannot be sufficiently emphasised that concepts, ideas and issues should be constantly revised and rethought. Deep historical wounds will not be healed by simply inviting people to come together to engage in dialogue in order to build a self- evaluation report. Renegotiating requires attempting to understand concepts and one another at the socalled 'metaphysical' level. This implies that a workshop be conducted prior to the completion of the self evaluation process and can be done by the unit of academic development or various faculty structures. The self-evaluation process needs to be exposed when it is dysfunctional and needs to be transformed when it demonstrates limitations. Moreover, where necessary, it should renegotiate relations between HODs from different disciplines who come to the table of discussion with different 'metaphysics'.

\section{References}

Bashir, A. (2002). Funding of Nigeria Universities: which way forward? Paper presented at the Academic Staff Union of Universities 
(ASUU) Seminar "The Plight of the University System in Nigeria: Any way out?" January 16, 2002. Federal University of Technology

Betzer, EM. (2010). Auniversity department as acommunity of practice: A quality promotion perspective. South African Journal of Higher Education 24:15-24.

Chetty, D. (2005). HE - Business Linkages: Shaping a New Economic Development Mission. Perspective on HE 2005-2014 SAUVCA Occasional Paper. Pretoria

Cohen, L., Manion, L. and Morrison, K. (2007). Research Methods in Education sixth edition London:Routledge falmer Publishers.

Department of Education (DOE), (2003). Revised Funding Framework (draft). Pretoria DoE).

Dill, D, (2003). The Catch 22' of Academic Quality: Implication for Universities and Public Policy. North Carolina, Public Policy for Academic Quality, North Carolina, University of North Carolina at Chapel Hill

Du Pre, R. (2000). Committee of Technikon Principals' Report. CTP. Pretoria.

Education White Paper 3 (1997): A Programme for the Transformation of HE, 1997. Pretoria: Department of Education.

Favish, J. (2005). Developing a framework for monitoring and enhancing HE contribution to social and economic development as part of a QA system. The decades ahead: Challenges of QA in South African HE. Sauvca Publicatio.

Fernandez, S., Fernandez, E. and Alvares, A. (2008). University institutional evaluation academic and academic achievement. Implementing and using QA: Strategy and Practice. A selection of Papers from the $1^{\text {st }}$ European Forum for QA. Sapienza Universita` di Roma, Italy.

Mapesela, M and Hay, D. (2005). Through the magnifying glass: A descriptive theoretical analysis of the possible impact of South African Higher Education policies on staff and job satisfaction. Higher Education Journal, 50: 111-128.

Harvey, L., (2004). 'The power of accreditation: views of academics', Journal of HE Policy and Management, 26: $207-223$.

Jacobs, D.J. (2000). A Future QA scenario for South African HE. South African Journal of HE, 14: 69-74.

Kasozi, A, (2006). Regulating Transnational HE in Uganda: Consumer Should be Cautious, The Uganda Higher Review, 3:30-32

Kowalkiewicz, A. (2007). The impact of quality culture on quality teaching- a case of business HE in Poland. Embedding quality culture in HE. A selection of Papers from the 1st European Forum for QA. Technische Universitat Munchen, Germany.

Kraak ,A. (2002). Investigating the Network Society: Industry-HE Partnerships in South Africa. Unpublished Project proposal. (Pretoria: Human Sciences Research Council

Luckett, K. and Kotecha, P. (2005). An analysis of Institutional Profiles: Implications for building a National QA System. Sauvca Occasional Publications and Reports (1).

McMillan, J.H. and Schumacher, S. (2007). Research in Education. New York: Pearson Education, United States of America.

Newton, J. (2007). What is quality?. Embedding quality culture in HE. A selection of Papers from the 1'st European Forum for QA. Technische Universitat Munchen, Germany.

Okebukola, P. (2006). QA in HE in Nigeria: Lessons for the African Region, UNESCO Harare Cluster Newsletter, 1

Republic of South Africa Department of Education and Training (1996). Green Paper on HE. Pretoria: Government Printer

Stensaker, B. (2007). Impact of quality processes. Embedding quality culture in HE. A selection of Papers from the $1^{\text {st }}$ European Forum for QA. Technische Universitat Munchen, Germany.

Szanto, T.R., (2003). 'Hungary - HE' in Educational Evaluation Around the World. An International Anthology (Copenhagen, the Danish Evaluation Institute) ISBN 87-7958-132-3.

Tempus, (2001). Glossary of the terms related to QA Development of QA System in HE (QUASYS) Tempus Joint European Project, UM JEP-16015-2001

Yorke, M and Lonngden, B. (2004). Retention and student success in HE. London: Falmer Press. 
